Dhaka Univ. J. Biol. Sci. 25(1): 83-90, 2016 (January)

\title{
IN VITRO EVALUATION OF FUNGICIDES AND PLANT EXTRACTS AGAINST THE FUNGI ASSOCIATED WITH SEEDS OF NINE CHICKPEA VARIETIES
}

\author{
Amina KHATUn AND SHAmim SHAmSi* \\ Department of Botany, University of Dhaka, Dhaka 1000, Bangladesh \\ Key words: Fungicides, Plant extracts, Fungi, Chickpea seeds
}

\begin{abstract}
A total of nine species of fungi were found to be associated with seeds of nine varieties of chickpea. The isolated fungi were Alternaria alternata (Fr.) Keissler, Aspergillus flavus Link., A. niger Van Tiegh., A. fumigatus Fresenius., A. nidulans Eidam, Curoularia lunata (Wakker) Boedijn, Penicillium Link., Rhizopus stolonifer (Ehrenb.: Fr.) Vuill and Trichoderma viride Pers. Five fungicides viz., Bavistin 50 WP, Dithane M-45, Greengel 72 WP, Ridomil MZ Gold and Tall 25 EC at 100, 200, 300,400 and 500 ppm were evaluated against the test fungi. Tall 25 EC were found most efficient inhibitor which completely inhibited the radial growth of the test fungi followed by Bavistin 50 WP, Dithane M-45 and Greengel 72 WP. Antifungal properties of ethanol extracts of Azadirachta indica A. Juss., Allium sativum L., Citrus medica L., Datura metel L. and Psidium guajava L. at 5, 10 and $20 \%$ concentrations were evaluated against the test fungi. Allium sativum L. was found most efficient inhibitor of the test fungi followed by D. metel L., A. indica A. Juss., C. medica L. and P. guajava L.
\end{abstract}

\section{Introduction}

Chickpea (Cicer arietinum L.) belongs to the family Fabaceae is one of the important pulse crops grown in Bangladesh. It is an important protein rich crop and occupied third position both in production and in acreage in pulse production of Bangladesh. Some major constraints have sharply declined its cultivation area and production for the last several years ${ }^{(1)}$. Chickpea is invaded by more than 50 diseases reported from different parts of the world (2-4). Most of the diseases are caused by fungi. In Bangladesh so far 17 chickpea diseases are recorded, 12 of which are caused by fungi(5). Out of 12 fungal diseases Botrytis grey mould (BGM), wilt, root rot, blight and collar rot are the major ones $^{(6)}$.

Chickpea seeds in storage, carry a mycoflora of 'field' and 'storage' fungi. Field fungi gradually disappear and storage fungi then predominant. Most of the storage pathogen species are Penicillium spp., Aspergillus spp. and Rhizopus spp. The storage fungi may cause discoloration of the seeds and germination failure ${ }^{(7)}$. These fungi especially grow

*Author for correspondence: <prof.shamsi@gmail.com> 
vigorously and initiate grain spoilage. They also bring about several undesirable changes making them unfit for consumption and sowing. Lot of research has been done in home and abroad on chickpea diseases and its control but information on storage mycoflora of chickpea seeds and its control are inadequate( ${ }^{(8-10)}$. Keeping this in view the present research work was undertaken to find out the fungi associated with chickpea seeds in stored condition. This paper also deals with the management of storage mycoflora associated with the chickpea seeds.

\section{Materials and Methods}

The present study is carried on storage seeds of chickpea. Seed samples of BARI chola 1-9 were collected from Bangladesh Agricultural Research Institute (BARI), Gazipur. Samples were collected after harvesting and placed in clean brown paper bags, labeled properly and preserved at $4^{\circ} \mathrm{C}$ in refrigerator for subsequent use.

The fungi were isolated from the samples following Tissue Planting Method on PDA medium $^{(11)}$ and Blotter method of ISTA. Two hundred seeds of each sample were placed on three layers of moist blotting paper (Whatman No. 1) in Petri plates. The seeds were washed with sterile water and then surface sterilized by dipping in $10 \%$ Chlorox solution for 5 minutes. Seeds were placed in each plate and incubated at $25 \pm 2^{\circ} \mathrm{C}$ for 5 - 7 days.

Fungi grown in the seeds were transferred to separate PDA slants for further studies and preservation. Identification of the isolates were determined based on morphological characteristics observed under a compound microscope following standard literature ${ }^{(12-17)}$. Percentage of prevalence of fungi in different specimens was also recorded.

In vitro efficacy of fungicides on the radial growth of test fungi were evaluated. Five fungicides with different active ingradient(s), viz., Bavistin 50 WP, Tall 25 EC, Ridomil MZ Gold, Dithane M-45 and Greengel 72 WP were collected from the Krishi Upokoron Biponi Kendro, Khamarbari, Farmgate, Dhaka. For each fungicide, a stock solution having the concentration of 10,000 ppm was prepared. The calculated amount of the stock solution of a fungicide was supplemented with sterilized PDA medium to get the final concentrations of 100, 200, 300, 400 and 500 ppm. Twenty $\mathrm{ml}$ of the supplemented medium of a particular concentration was poured in sterilized Petri plates and allowed to solidify. In the control set, required amount of sterile water instead of fungicide was added to the PDA medium. Then it was inoculated in the centre of the plate with a $5 \mathrm{~mm}$ of mycelial agar disc. Three replications were maintained in both the cases.

Efficacy of five plant extracts viz., Azadirachta indica A. Juss., Allium sativum L., Citrus medica L., Datura metel L. and Psidium guajava L. were evaluated against the same fungi. The desired parts of each plant were thoroughly washed in tap water, air dried and then used for preparation of extract. Leaf extracts were prepared by crushing known weight of fresh materials with ethanol in ratio of $1: 1(\mathrm{w} / \mathrm{v})$. The mass of a plant part was squeezed 
through fine cloth and the extracts were centrifuged at $3000 \mathrm{rpm}$ for 20 minutes. The supernatants were filtered through Whatman filter paper No. 1 and the filtrate was collected in $250 \mathrm{ml}$ Erlenmeyer conical flasks. The requisite amount of the filtrate was mixed with PDA medium in which plant extracts were in 5, 10 and 20\% concentrations.

The radial growth of the colonies was measured at the 5th day of incubation. The per cent of growth inhibition of each test fungi was calculated by the formula described by Bashar and Rai(18).

\section{Results and Discussion}

A total of 9 species of fungi belongs to 6 genera and a sterile fungus were found to be associated with seeds of 9 varieties (BARI chola 1-9) of chickpea. The isolated fungi were Alternaria alternata (Fr.) Keissler, Aspergillus flavus Link, A. niger Van Tiegh., A. fumigatus Fresenius, A. nidulans Eidam, Curvularia lunata (Wakker) Boedijn, Penicillium Link, Rhizopus stolonifer (Ehrenb.: Fr.) Vuill and Trichoderma viride Pers. The frequently associated fungi with seeds of chickpea were A. alternata, A. flavus, A. fumigatus, C. lunata and Penicillium sp. and these fungi were tried to control with selected fungicides and plant extracts.

Amongst the 5 fungicides used in the present investigation, Bavistin 50 WP, Dithane M-45 were systemic while Tall 25 EC was protective fungicides. Complete inhibition of the test pathogens were observed with Tall $25 \mathrm{EC}$ at all the concentrations used and other fungicides inhibited the radial growth of the pathogen at different grades (Fig. 1 a-e).

Dithane M-45 and Tall 25 EC were responsible for complete inhibition of the radial growth of A. alternata at all the concentrations. Greengel $72 \mathrm{WP}$ also showed $100 \%$ inhibition at 500 ppm whereas Bavistin and Ridomil showed only 73.33 and $66.67 \%$ inhibition at the same concentration. Bavistin, Greengel and Ridomil at $400 \mathrm{ppm}$ concentration showed 66.67, 73.33 and $60.0 \%$ growth inhibition, respectively (Fig. 1a).

Amongst the 5 fungicides, Bavistin $50 \mathrm{WP}$, Tall $25 \mathrm{EC}$ and Greengel $72 \mathrm{WP}$ at different concentrations showed $100 \%$ inhibition of the radial growth of A. flavus. Ridomil MZ GOLD and Dithane M-45 showed 50\% inhibition at 500 ppm and $42.86 \%$ inhibition at 400 ppm concentration (Fig. 1b).

Tall 25 EC and Bavistin 50 WP were completely inhibited the radial growth of A. fumigatus at all the concentrations used in the present study. Dithane M-45 also inhibited the radial growth completely at 500 ppm whereas Greengel 72 WP showed $54.55 \%$ and Ridomil MZ GOLD showed 60\% inhibition (Fig. 1c).

The complete inhibition of the radial growth of Curvularia lunata was observed with Tall 25 EC at all the concentrations tested. Bavistin $50 \mathrm{WP}$ and Greengel $72 \mathrm{WP}$ also showed $100 \%$ inhibition of growth at 400 and $500 \mathrm{ppm}$ concentrations whereas the per 
cent inhibition of Dithane M-45 and Ridomil MZ Gold was not so good. They showed 76.66 and $74.78 \%$ inhibition at 500 ppm concentration, respectively (Fig. 1d).

Growth of the Penicillium sp. was completely inhibited with Tall 25 EC at all concentrations used. Bavistin 50 WP and Greengel 72 WP showed 100\% inhibition at 500 ppm and 70\% inhibition at $400 \mathrm{ppm}$ concentration. Dithane and Ridomil inhibited 75.0 and $83.34 \%$ growth of the fungus at $500 \mathrm{ppm}$ concentration and 64.29 and $42.86 \%$ inhibition at 400 ppm concentration, respectively (Fig. 1e).

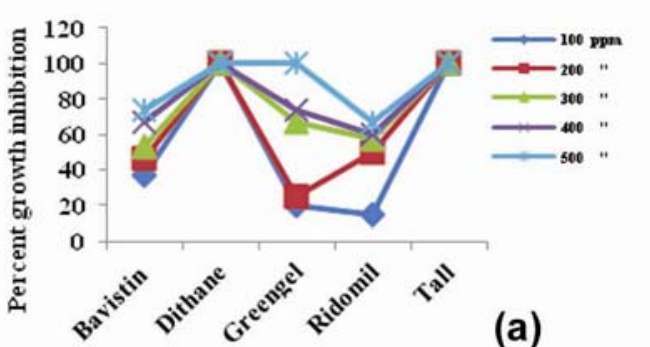

Fungicides

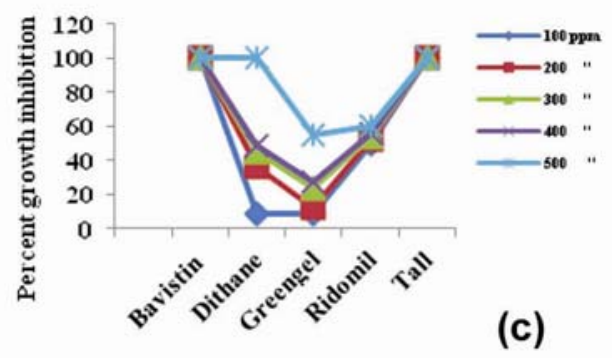

Fungicides
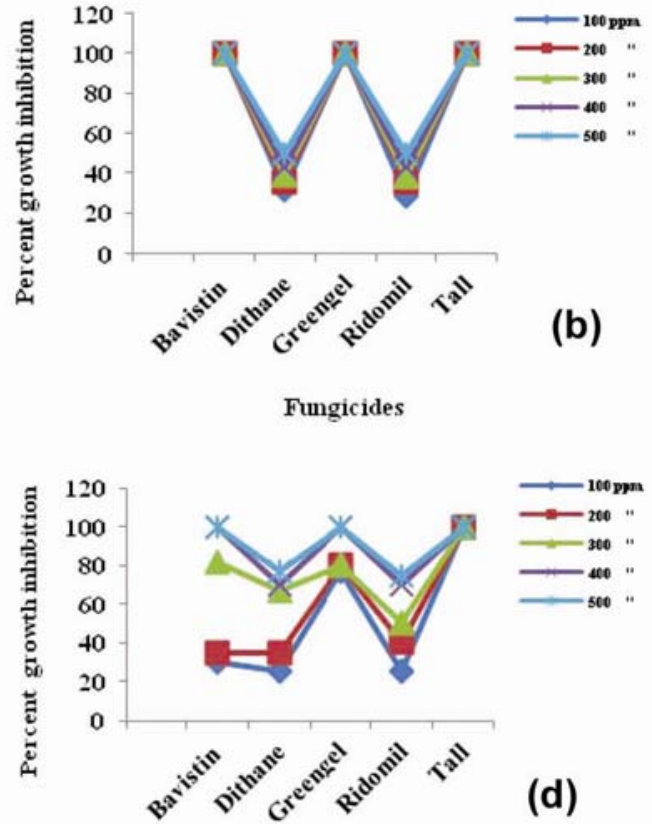

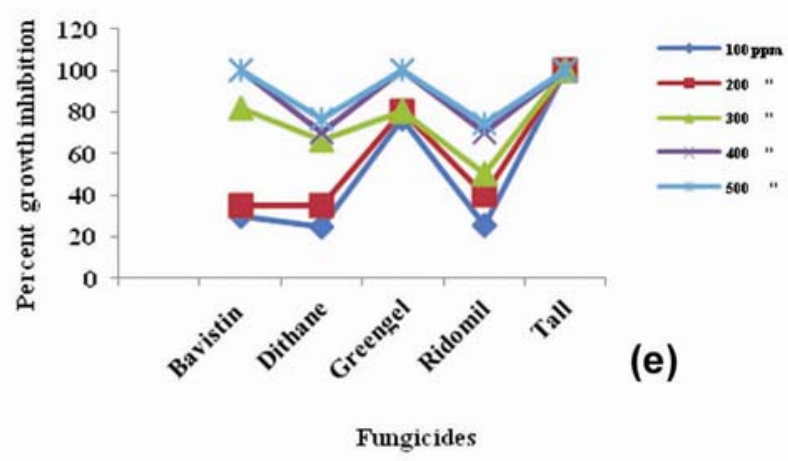

Fig. 1. Per cent inhibition of radial growth of a. Alternaria alternata, b. Aspergillus flavus, c. A. fumigatus, d. Curvularia lunata and e. Penicillium sp. owing to fungicides at different concentrations. 
Amongst the five fungicides, Tall 25 EC showed best result and Bavistin 50 WP showed least percentage of inhibition.

Antifungal properties of ethanol extracts of five plant parts viz., Azadirachta indica, Allium sativum, Citrus medica, Datura metel and Psidium guajava at 5, 10 and 20\% concentrations were evaluated on the test fungi. Allium sativum was found most efficient inhibitor of the test fungi followed by D. metel, A. indica, C. medica and P. guajava (Fig. 2 a-e).

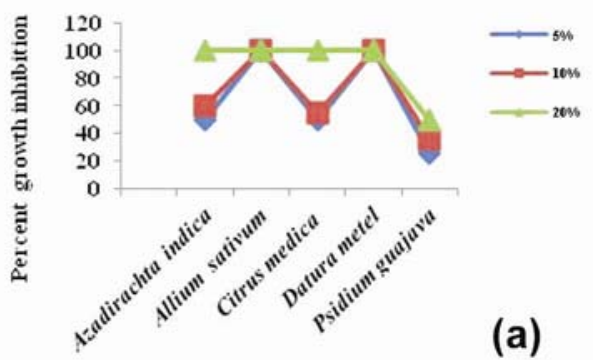

Plant extracts

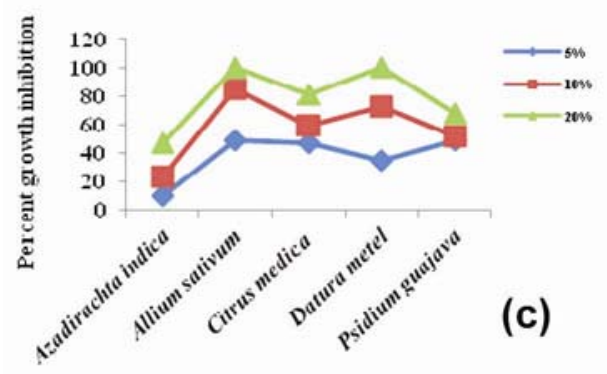

Plant extracts

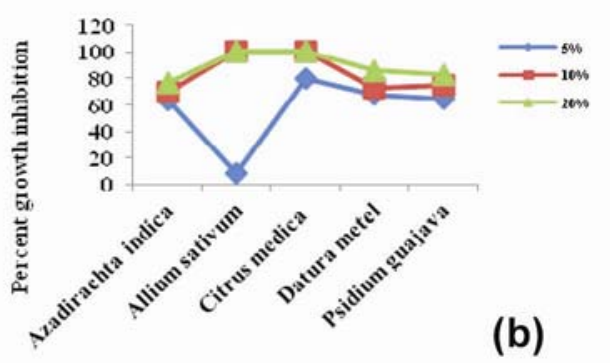

Plant extracts
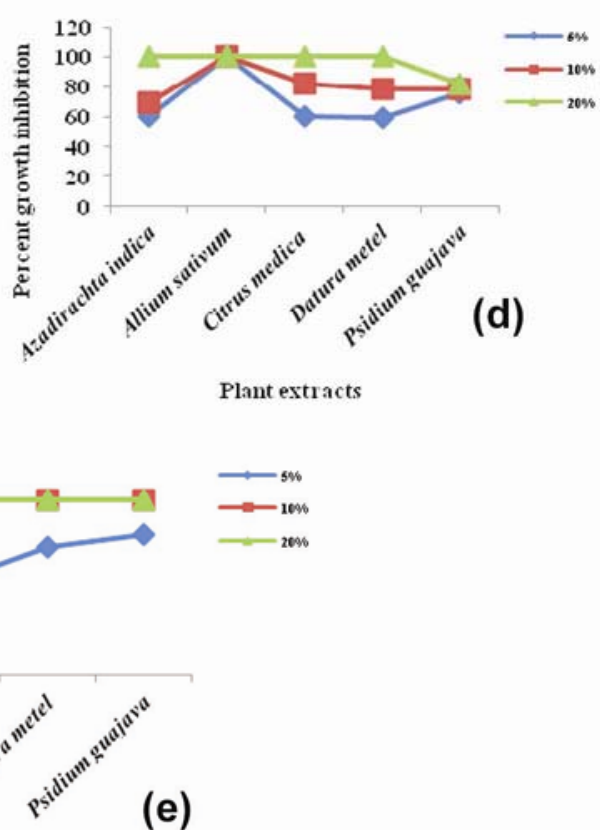

(e)

Plant extracts

Fig. 2. Per cent inhibition of radial growth of a. Alternaria alternata, b. Aspergillus flavus, c. A. fumigatus, d. Curvularia lunata and e. Penicillium sp. owing to plant extracts at different concentrations. 
Amongst 5 plant extracts used in this experiment ethanol extract of Datura metel and Allium sativum showed complete inhibition of radial growth of Alternaria alternata at all the concentrations. Citrus medica and Azadirachta indica also showed 100\% inhibition at $20 \%$ concentration whereas Psidium guajava showed 50\% inhibition at the same concentration. C. medica, A. indica and P. guajava showed 55.0, 60.0 and $35.0 \%$ growth inhibition, respectively at $10 \%$ concentration. (Fig. 2a).

Ten and 20 per cent ethanol extracts of $A$. sativum and $C$. medica were responsible for complete inhibition of radial growth of $A$. flavus whereas the $20 \%$ concentration of $A$. indica, D. metel and P. guajava showed $77.05,86.0$ and $83.5 \%$ inhibition of the fungal growth, respectively. These 3 ethanol plant extracts showed 70.0, 72.5 and $75.0 \%$ inhibition at $10 \%$ concentration (Fig. 2 b).

Twenty per cent ethanol extracts of Allium sativum and Datura metel were responsible for $100 \%$ inhibition of the radial growth of A. fumigatus whereas A. indica, C. medica and P. guajava showed $46.67,81.25$ and $67.74 \%$ inhibition of the fungus at the same concentration. The ethanol extracts of A. indica, A. sativum, C. medica, Datura metel and $P$. guajava showed $23.33,84.62,59.36,73.08$ and $51.62 \%$ inhibition at $10 \%$ concentration, respectively (Fig. 2c).

Ethanol extract of $A$. sativum showed $100 \%$ inhibition of radial growth of Curvularia lunata at all the concentrations used. Twenty percent concentration of A. indica, C. medica and D. metel also showed complete inhibition of Curvularia lunata whereas $P$. guajava showed $81.82 \%$ inhibition at the same concentration. The extracts of $A$. indica, C. medica, D. metel and P. guajava showed $69.70,81,82,78.13$ and $78.79 \%$ inhibition of the growth at $10 \%$ concentration, respectively (Fig. $2 \mathrm{~d}$ ).

Twenty per cent ethanol extracts of A. indica, A. sativum, C. medica, D.metel and P. guajava were responsible for complete inhibition of radial growth of Penicillium sp. $10 \%$ ethanol extract of these 5 plants also showed 100\% inhibition except $A$. sativum which showed $80.34 \%$ inhibition (Fig. 2e).

The extract of different parts of higher plants have been reported to exhibit antifungal properties under laboratory trials ${ }^{(19)}$. Plant parts and their constituents of some higher plants have already been reported to be of successful nature of fungitoxicant because of their lesser phytotoxicity, systemicity, easily vertigratability and favourable effect for the growth of host.

Bashar and Rai(18) have reported that lime fruit peel essential oil components inhibit linear growth on spore germination of $P$. italicum, P. digitatum and Geotrichum canium.

Mohana et al.(19) from India reported that methanol extracts of Acacia nilotica, Caesalpinia coriaria, Decalepis hamiltonii, Emblica officinalis and Mimosops elengi showed significant antifungal activity at $3500 \mu \mathrm{g} / \mathrm{ml}$ concentration on seed pathogens viz., Alternaria alternata, Aspergillus flavus, Curvularia lunata, Drechslera oryzae, D. halodes, 
Fusarium moniliforme, Pyricularia oryzae and Trichoconis padwickii by poisoned food technique.

Chowdhury et al.(20) reported that the presence of 5 pathogenic fungi viz., Alternaria alternata, Curvularia lunata, Drechslera oryzae, Fusarium moniliforme and Pestalotiopsis guepinii associated with rice grains were completely controlled in vitro at different concentrations of Tall 25 EC. Antifungal activity of ethanol extracts of Tagetes erecta, Datura metel, Senna alata, Azadirachta indica, Citrus medica, Mangifera indica, Artocarpus heterophyllus, Asparagus racemosus, Nerium indicum and Allium sativum completely inhibited the radial growth of the test fungi at $20 \%$ concentration.

Singh and Singh(9) treated the seeds of Broad bean (Vigna faba) with Dithane M-45, Ceresan, Bavistin and Vitavax. Among the treatments seed borne mycoflora was most effectively controlled by Dithane M- 45.

Salam ${ }^{(10)}$ worked with storage chickpea seeds collected from two different locations. Aspergillus flavus, A. niger, Fusarium oxysporum, F. Moniliforme, Penicillium notatum, Alternaria alternata, Sclerotium rolfsii and Botrytis cinera were found to be associated with the stored seeds. He tested the efficacy of Vitavex- 200 and hot water treatment on the fungi associated with chickpea seeds and found seed treatment with Vitavex-200 at the rate of $2.5 \mathrm{~g} / \mathrm{kg}$ and $56^{\circ} \mathrm{C}$ hot water showed the most effective results.

\section{Acknowledgements}

This study was supported by a NST Fellowship of the "Ministry of Science and Technology, Government of Bangladesh.

\section{References}

1. Bakr MA, KHM Siddique and C Johansen 2002. Integrated management of BGM of chickpea in Bangladesh and Australia: Summary proceedings of a Project Inception Workshop, 1-2 June, 2002, BARI, Joydebpur, Gazipur, Bangladesh. pp. 19-32.

2. Nene YL 1980. Diseases of Chickpea. Proceedings, International Workshop on Chickpea Improvement. ICRISAT, 28 Feb - 2 Mar, 1979. Hyederabad, India. pp. 171-178.

3. Ahmed HU 1985. Disease problems of pulses and oilseed crops in Bangladesh. Presented in the First Biennial Conference of the Bangladesh Phytopathological Society, 13-14 April 1985, BARI, Joydebpur, Gazipur, Bangladesh.

4. Fakir GA 1983. Status of Research on Pulse Disease at the Bangladesh Agricultural University (BAU), Mymensingh. Department of Plant Pathology, BAU, Mymensingh. pp.19.

5. Bakr MA, HU Ahmed, MA Ahmed and MA Wadud Mian 2007. Advances in Plant Pathological Research in Bangladesh. Proceedings of the National Workshop on "Strategic Intervention on Plant Pathological Research in Bangladesh",11-12 February 2007, Plant Pathology Division, Bangladesh Agricultural Research Institute, Joydebpur, Gazipur, Bangladesh. pp. 344 . 
6. Bakr MA 1994. Check list of Pulse Diseases in Bangladesh. Bangladesh J. Plant Path. 10(1\&2): 10-13.

7. BARI 1986. Annual Report 1985/86, Plant Pathology Division, BARI, Joydebpur, Gazipur, Bangladesh. pp. 119.

8. Petkar AS, PG Utikar and BB More 1997. Control of collar rot of double bean causing by Macrophomina phaseolina. Mysore J. Agric. Sci. 11(1): 63-65.

9. Singh SN and NI Singh 1986. Seed mycoflora of broad bean and its control. Indian Phytopathology. 39(4): 541-543.

10. Salam MA 2004. Mycoflora of stored chickpea seeds and their control, MS Thesis, Dept. of Plant Pathology, BAU, Mymensingh. pp. 73.

11. CAB 1968. Plant Pathologist's Pocket Book. 1st edition. The Commonwealth Mycological Institute, England. pp. 267.

12. Barnett HL and SB Hunter 1972. Illustrated Genera of Imperfect Fungi. 3rd. Ed. Burgess Publishing Company, U.S.A. pp. 44-45.

13. Booth C 1971. The Genus Fusarium. The Commonwealth Mycological Institute, Kew, England. pp. 267.

14. Ellis MB 1971. Dematiaceous hyphomycetes. The Commonwealth Mycological Institute, England. pp. 608.

15. Ellis MB 1976. More Dematiaceous hyphomycetes. The Commonwealth Mycological Institute, England. pp. 507.

16. Ellis MB and JP Ellis 1997. Micro Fungi on Land Plants. An Identification Handbook. The Richmond Pub. Co. Ltd. pp. 868.

17. Sutton BC 1980. The Coelomycetes. Fungi Imperfecti with Pycnidia, Acervuli and Stroma. The Commonwealth Mycological Institute, England. pp. 696.

18. Bashar MA and B Rai 1991. Antiungal property of extracts of some plant parts against Fusarium oxysporum f. sp. ciceri. Bangladesh J. Bot. 20 : 219-222.

19. Mohana DC, P Prasad, V Vijaykumar and KA Raveesha 2011. Plant extract effect on seed borne pathogenic fungi from seeds of paddy grown in Southern India. J. Plant Protection Res. 51: 102-106.

20. Chowdury P, MA Bashar and S Shamsi 2015, In vitro evaluation of fungicides and plant extracts against pathogenic fungi of two rice varieties in Bangladesh. Bangladesh J. Bot. 24(2): 251-259. 